\title{
Hepatocellular Carcinoma Complicating Hepatitis E Virus-Related Cirrhosis
}

\author{
Patrick Borentain (D), ${ }^{1 *}$ Philippe Colson, ${ }^{2 *}$ Emilie Bolon, ${ }^{3}$ Philippe Gauchez, ${ }^{4}$ Diane Coso, ${ }^{5}$ and René Gérolami ${ }^{1}$
}

$\mathrm{H}$ epatitis $\mathrm{E}$ virus (HEV) was revealed in 2008 as a new cause of chronic hepatitis and cirrhosis in immunocompromised patients. ${ }^{(1,2)}$ Chronic hepatitis $\mathrm{E}$ results in liver inflammation and fibrosis that may lead to liver cirrhosis. To date, however, no case of HEV-related hepatocellular carcinoma (HCC) has been reported. We present a case of HCC complicating chronic hepatitis E.

\section{Clinical Observation}

A 65-year-old man was diagnosed with a liver mass by ultrasonography in November 2015. This patient had been treated for follicular lymphoma between 1999 and 2004 (rituximab, cyclophosphamide, doxorubicin [hydroxydaunomycin], vincristine [oncovin], and prednisone, followed by autologous stem-cell transplantation and rituximab). Since May 2004 the patient was considered cured of his lymphoma and did not receive specific therapy. However, he presented cerebral toxoplasmosis, necessitating surgical therapy in December 2005, with a relapse in November 2006 that was medically treated. At admission, biological tests showed liver cytolysis (alanine aminotransferase, 164 IU/L; aspartate aminotransferase, 117 IU/L; gammaglutamyltransferase, $246 \mathrm{IU} / \mathrm{L}$; alkaline phosphatase, $91 \mathrm{IU} / \mathrm{L})$. Serum bilirubin $(3 \mu \mathrm{mol} / \mathrm{L})$, albumin $(43 \mathrm{~g} /$ $\mathrm{L})$, and international normalized ratio (0.94) were normal. Serum alpha-fetoprotein level was $50 \mathrm{ng} / \mathrm{mL}$. A computed tomographic scan showed a $25-\mathrm{mm}$ hypervascular liver nodule with a washout during the portal phase. Nontumoral liver biopsy showed histological cirrhosis with mononuclear infiltrate suggestive of chronic viral hepatitis. HCC complicating Child-Pugh A cirrhosis was diagnosed, and the patient underwent tumor resection. At the time of surgery the liver was nodular, and histological examination confirmed cirrhosis and HCC (Fig. 1).

Retrospective analysis of liver biological tests showed chronic liver cytolysis since 2007 (Fig. 1). The patient, a butcher, did not report any chronic alcohol intake or uncooked pork meat consumption. All other major etiologies of chronic hepatitis were ruled out: serology for hepatitis $\mathrm{B}$ virus and hepatitis $\mathrm{C}$ virus was negative. The patient did not present metabolic syndrome, and his body mass index was lower than $25 \mathrm{~kg} / \mathrm{m}^{2}$. Serum ferritin was normal, and liver-directed autoantibodies were all negative. HEV testing performed in November 2015 showed the presence of immunoglobulins $G$ and $\mathrm{M}$ (Wantai, China) and HEV RNA (quantitative real-time $\mathrm{PCR}^{(3)} ; 6.2 \log _{10}$ copies $/ \mathrm{mL}$ ) in the serum. In addition, serum collected 6 months earlier tested retrospectively positive for HEV RNA (6.1 $\log _{10}$ cop- $^{-}$ ies $/ \mathrm{mL})$. HEV open reading frame 2 sequencing $^{(3)}$ showed that virus was of genotype 3 (GenBank accession no. KX580027-KX580034). HEV RNA was also detected by quantitative real-time PCR in tumorous and nontumorous liver. HEV open reading frame 2 sequences obtained from serum collected at the time of liver surgery and 8 months earlier were $99 \%$ identical to each other. Ribavirin therapy administered from January 2016 through March 2016 resulted in the rapid normalization of liver transaminases concurrently with HEV RNA clearance (Fig. 1).

Abbreviations: HCC, hepatocellular carcinoma; HEV, hepatitis E virus.

Received May 30, 2017; accepted August 13, 2017.

*These authors contributed equally to this work.

Copyright $\odot 2017$ by the American Association for the Study of Liver Diseases.

View this article online at wileyonlinelibrary.com.

DOI 10.1002/hep.29508

Potential conflict of interest: Nothing to report. 


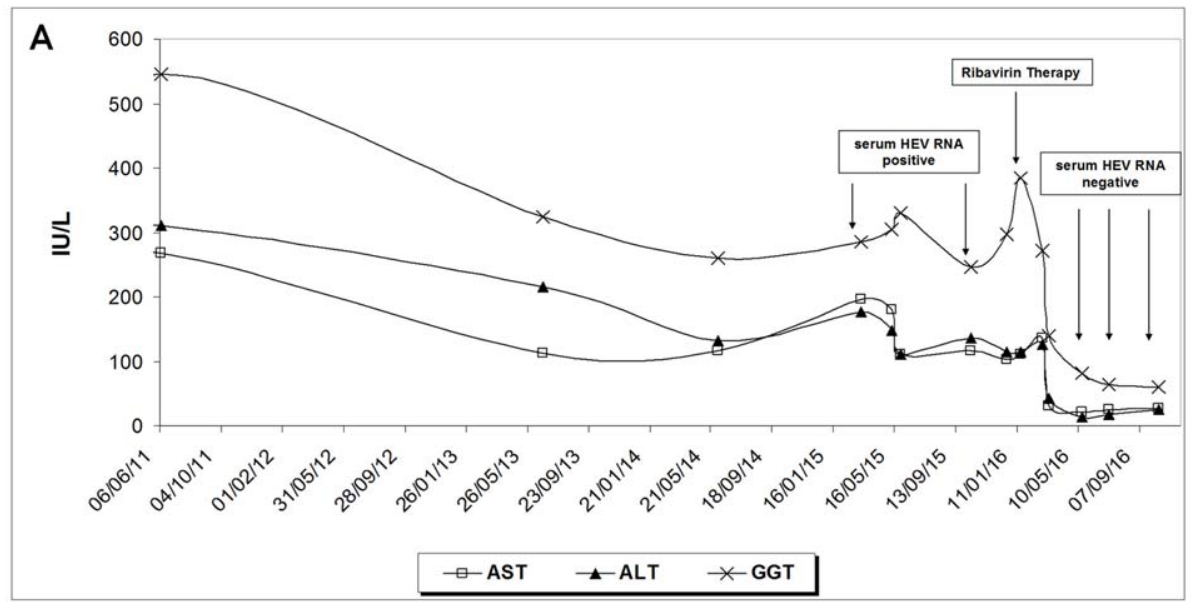

FIG. 1. (A) Evolution of liver biological tests. Alanine aminotransferase (ALT), aspartate aminotransferase (AST), and gamma-glutamyltransferase (GGT) levels were found within normal range up to 2004. From 2006 to diagnosis of HCC (November 2015) ALT, AST, and GGT levels fluctuated between 5-fold and 10-fold the normal range. Results are presented from 2011 to 2016. (B-E) Histological examination of liver. (B) Typical pattern of liver cirrhosis in the nontumoral liver showing sirius red staining of collagen, original magnification $\times 50$. (C) Tumor examination showing atypical hepatocytic cellular proliferation. Hematoxylin, phloxine, and saffron staining, $\times 200$. (D) Loss of sinusoidal architecture. Reticulin staining, $\times 200$. (E) Anti-cluster of differentiation 31 immunostaining showing capillarization of tumorous endothelial cells.
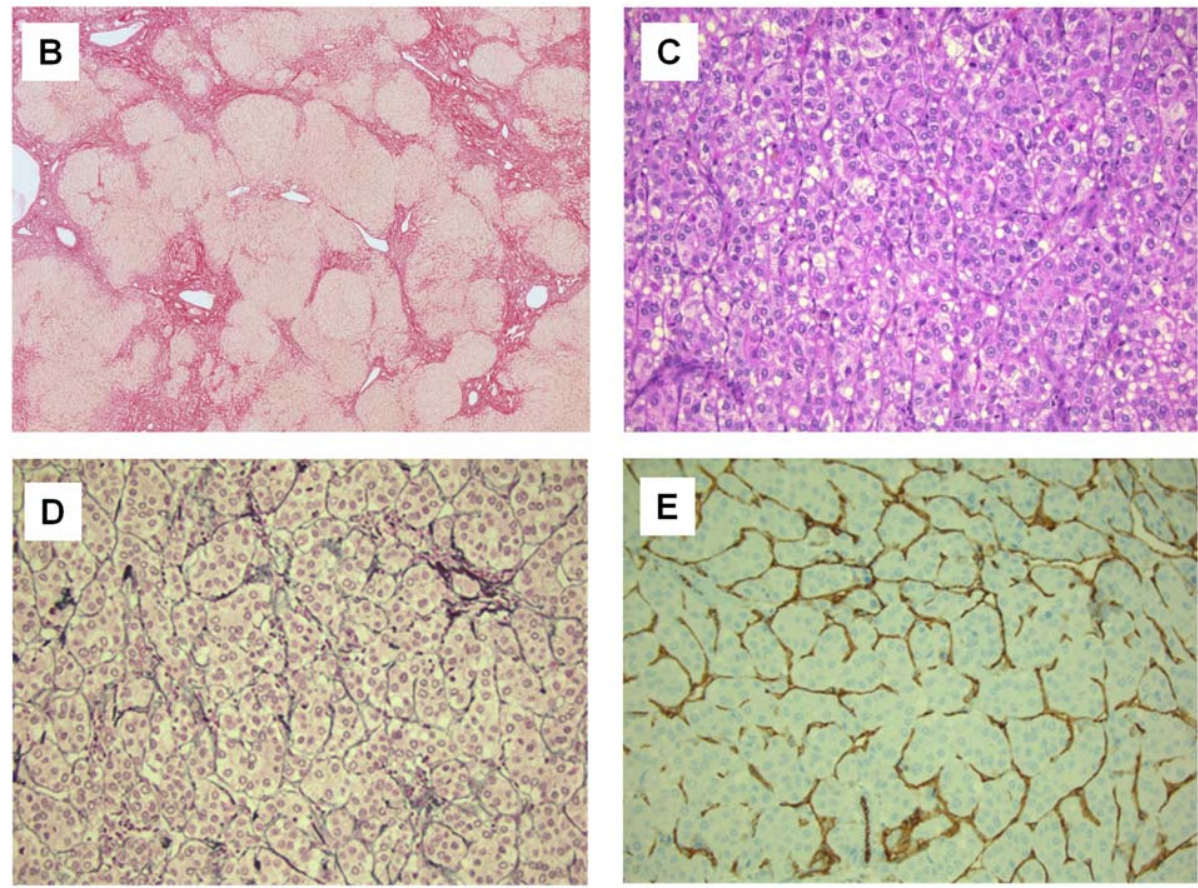

\section{ARTICLE INFORMATION:}

From the ${ }^{1}$ Service d'Hépato-Gastro-Entérologie, Assistance Publique des Hôpitaux de Marseille, Centre Hospitalo-Universitaire Timone; ${ }^{2}$ URMITE, Aix Marseille Université, UM63, CNRS 7278, IRD 198, INSERM 1095, IHU-Méditerranée Infection, Assistance Publique des Hôpitaux de Marseille; ${ }^{3}$ Service de Chirurgie Digestive et Transplantation Hépatique, Assistance Publique des Hôpitaux de Marseille, Centre Hospitalo-Universitaire Timone; ${ }^{4}$ Service d'Anatomopathologie, Assistance Publique des Hôpitaux de Marseille, Centre HospitaloUniversitaire Timone; ${ }^{5}$ Département d'Hématologie, Institut Paoli Calmettes, Marseille, France.

\section{ADDRESS CORRESPONDENCE AND REPRINT REQUESTS TO:}

Patrick Borentain, M.D., Ph.D.

Service d'Hépato-Gastro-Entérologie, Assistance Publique des Hôpitaux de Marseille

Centre Hospitalo-Universitaire Timone
264 rue Saint-Pierre

13385, Marseille Cedex 05, France

E-mail: patrick.borentain@ap-hm.fr 


\section{Discussion}

In the present observation, chronic hepatitis $\mathrm{E}$ developed, although therapy for lymphoma was completed since 2004. This is unusual. Nevertheless, cerebral toxoplasmosis in 2005-2006 and hypogammaglobulinemia at the time of HCC diagnosis indicated that the patient has remained severely immunocompromised. In addition, the absence of other possible etiologies and the rapid normalization of liver tests in parallel with $\mathrm{HEV}$ RNA clearance suggest that HEV was the cause of chronic hepatitis in this patient since 2007.

Chronic HEV infection is not a classical cause of HCC. This could be explained by the overall small number of HEV-related chronic hepatitis and cirrhosis cases worldwide ${ }^{(3)}$ and the efficacy of ribavirin therapy. ${ }^{(4)}$ Thus, in our institution, only 2 patients were diagnosed with $\mathrm{HEV}$-associated cirrhosis, including the present case who developed HCC. ${ }^{(5)}$ As suspected for $\mathrm{HCV}, \mathrm{HEV}$ infection may promote $\mathrm{HCC}$ through chronic inflammation. Specific mechanisms involved in liver carcinogenesis remain to be investigated.
In conclusion, $\mathrm{HEV}$ joins hepatitis $\mathrm{B} / \mathrm{C}$ viruses as a potential cause of $\mathrm{HCC}$ in chronically infected patients. This observation highlights the importance of diagnosing and treating chronic $\mathrm{HEV}$ infection in immunosuppressed patients to prevent evolution toward liver cirrhosis and HCC, and it warrants systematic testing for $\mathrm{HEV}$ infection in patients with HCC of unknown cause.

\section{REFERENCES}

1) Gérolami R, Moal V, Colson P. Chronic hepatitis $E$ with cirrhosis in a kidney-transplant recipient. N Engl J Med 2008;358:859-860.

2) Kamar N, Selves J, Mansuy JM, Ouezzani L, Péron JM, Guitard $\mathrm{J}$, et al. Hepatitis $\mathrm{E}$ virus and chronic hepatitis in organ-transplant recipients. N Engl J Med 2008;358:811-817.

3) Kamar N, Bendall R, Legrand-Abravanel F, Xia NS, Ijaz S, Izopet J, et al. Hepatitis E. Lancet 2012;379:2477-2488.

4) Mallet V, Nicand E, Sultanik P, Chakvetadze C, Tessé S, Thervet $\mathrm{E}$, et al. Brief communication: case reports of ribavirin treatment for chronic hepatitis E. Ann Intern Med 2010;153:85-89.

5) Moal V, Legris T, Burtey S, Morange S, Purgus R, Dussol B, et al. Infection with hepatitis $\mathrm{E}$ virus in kidney transplant recipients in southeastern France. J Med Virol 2013;85:462-471. 